\title{
Mid-Dermal Elastolysis on Face, Unusual Localization: A Case Report
}

\author{
Ebru Zemheria, Burcin Subasia ${ }^{a}$ Ilkin Zindanci ${ }^{b}$, Seyma Ozkanlia, ${ }^{\mathrm{a}}$, \\ Tulay Zenginkinet ${ }^{\mathrm{a}}$, Ayse Serap Karadag ${ }^{\mathrm{b}}$
}

\begin{abstract}
Mid-dermal elastolysis (MDE) is a rare disorder and an acquired skin condition of the elastic tissue generally affecting young women on the trunk and proximal extremities, rarely the thighs and the face. We report a case of a patient with an unusual face presentation of this disorder, supporting the concept that MDE is an idiopathic distinct entity.
\end{abstract}

Keywords: Mid-dermal elastolysis; Dermatology; Pathology; Skin disorder

\section{Introduction}

First described in 1977 by Shelley and Wood, mid-dermal elastolysis (MDE) is a rare disorder [1]. MDE is an acquired skin condition of the elastic tissue generally affecting young women on the trunk and proximal extremities, rarely the thighs and face [2-4]. We present a case of a patient with an unusual face presentation of this disorder, supporting the concept that MDE is an idiopathic distinct entity.

\section{Case Report}

A 53-year-old white woman, presented with a 2-year history of asymptomatic, widespread, well-demarcated but irregularly shaped areas of skin fine wrinkling. Dermatologic

\footnotetext{
Manuscript accepted for publication April 11, 2014

${ }^{a}$ Department of Pathology, Istanbul Medeniyet University, Goztepe Training and Research Hospital, Istanbul, Turkey

${ }^{\mathrm{b}}$ Department of Dermatology, Istanbul Medeniyet University, Goztepe Training and Research Hospital, Istanbul, Turkey

${ }^{\circ}$ Corresponding author: Seyma Ozkanli, Tutuncu Mehmet Efendi Cad.

Karanfil Sok. Ugur Apt. No. 16/3 Goztepe, Istanbul, Turkey.

Email: seymaozkanli@gmail.com

doi: http://dx.doi.org/10.14740/jmc1771w
}

examination reveals minimally raised papular yellow-skin colored lesions in chin, cheeks and forehead. These lesions were firm and linearly arranged in some areas (Fig. 1). These lesions first appeared on forehead slowly spreading to her face. Subsequently, there was no family history of similar lesions, cutaneous disease, or connective tissue disease. In patient questioning, we learned that due to the early menopause, estradiol $(2 \mathrm{mg})$ and norethisterone acetate preparation $(1 \mathrm{mg})$ were used for 10 years, and that these lesions occurred in the last 1 year of drug use.

Histologically, basket-weave keratosis, normal epidermis, eosinophilic homogenization on mid-dermis and lymphocytic infiltration around vessels were seen on H\&E section (Fig. 2). Elastic von Gieson stain revealed focal loss of elastic fibers in the mid-dermis (Fig. 3). Our case was compatible with MDE [2] because of the skin appearance of peau d'orange and histopathological findings.

\section{Discussion}

MDE is a rare, acquired condition affecting mid-dermis presented by band-like loss of elastic tissue limited to the middermis [5] MDE and it usually affects women in their third to fifth decades of life [6].

Clinically, MDE is divided as three subtypes: type I: parallel arranged plaques of fine wrinkling to skin cleavage lines; type II: perifollicular papular protrusions with "peau d'orange" appearance; and type III: persistent reticular erythema, especially upper trunk $[2,6]$. The characterization of this disease lesions involves the trunk and arms, and rarely, the thighs and face [3].

Histologically, band-like loss of elastic fibers in the middermis is diagnostic. Inflammatory infiltrates may be present and vary in degree; elastophagocytosis and giant cells are occasionally noticed [2].

Ultra-structural studies reported macrophages phagocyte aberrant dense substance collections, loose aggregates of skeleton fibrils and degenerated elastic fibers [7]. In addition, elastic fibers may be fragmented in MDE [8].

We still do not exactly know how elastolysis occurs. Some patients who were reported to have MDE also have an 


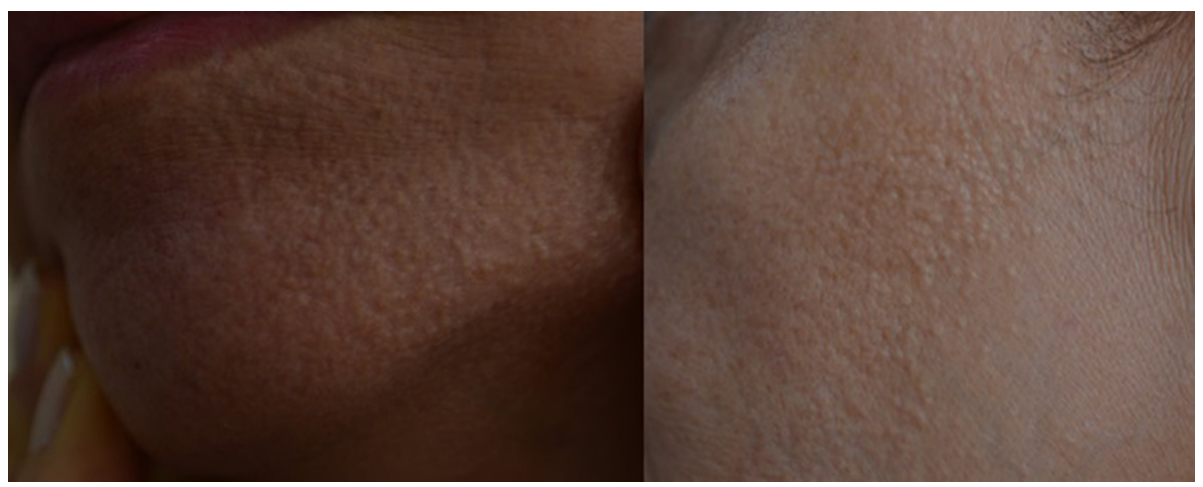

Figure 1. A female patient with perifollicular papular protrusions with "peau d'orange" appearance on chin and cheeks.

autoimmune disease like rheumatoid arthritis or Hashimoto's thyroiditis. About one-fourth of the patients have story of oral contraceptive usage $[4,9]$. Men get ill remarkably older than women [2]. This interesting difference between the ages of onset may be explained by the hormone level variability between men and women [2]. Aging is strongly related with collagen and elastin damage. Smoking is a wellknown cause of aging of the skin and the face is particularly affected. Patroi et al have tried to find out if there is a connection between smoking and MDE [4]. It is reported that MDE is aggravated by exposure to prolonged and intense UV light. Despite this, MDE is less common in areas which are considerably sun-exposed such as face and hands. Therefore, the suggestion that UV radiation is essential in the pathogenesis MDE is still suspicious [4].

Although MDE and some other inflammatory skin diseases such as urticaria, atopic dermatitis and granuloma annular are reported together, the pathogenetic relation between MDE and these diseases is unclear [2, 4].

In differential diagnosis, pseudoxanthoma elasticumlike papillary dermal elastolysis may resemble type II MDE. In contrast to pseudoxanthoma elasticum-like papillary der-

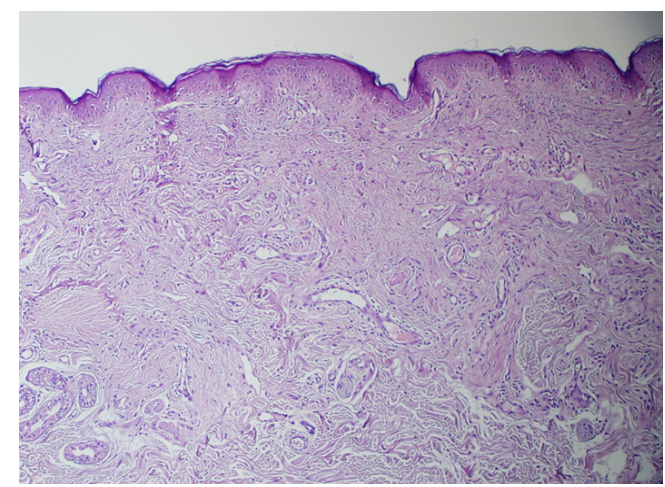

Figure 2. Basket-weave keratosis, normal epidermis, eosinophilic homogenization on mid-dermis and lymphocytic infiltration around vessels $(\mathrm{H} \& \mathrm{E}, \times 20)$. mal elastolysis, MDE is characterized by perifollicular papular protrusions and a band-like loss of elastic tissue in the mid-dermis [5].

Finally, we reported a case with a rare localization, facial occurrence, rather than the classic full body occurrence. The lesion occurring in a highly sun-exposed part of the body may support Patroi et al's theory that exposure to UV starts elastolysis. Besides, we believe that our case's history of long-term usage of preperates including estrogen-progesterone may have a part in the etiological process of the lesion.

\section{References}

1. Shelley WB, Wood MG. Wrinkles due to idiopathic loss of mid-dermal elastic tissue. Br J Dermatol. 1977;97(4):441-445.

2. Streams NB, Williams JM, Moschella SM. Mid-Dermal Elastolysis, Presented at the New England Dermatological Society Meeting, Boston, Massachusetts, February 9, 2002.

3. Bannister MJ, Rubel DM, Kossard S. Mid-dermal elas-

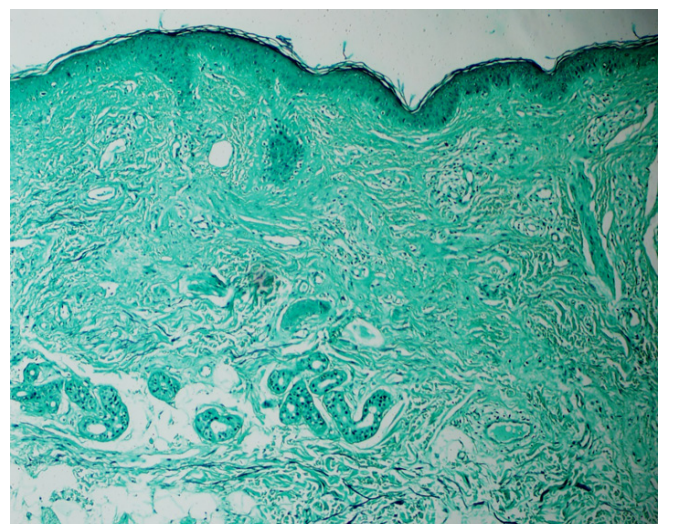

Figure 3. Loss of elastic fibers in the mid-dermis (elastic van Gieson, × 20). 
tophagocytosis presenting as a persistent reticulate erythema. Australas J Dermatol. 2001;42(1):50-54.

4. Patroi I, Annessi G, Girolomoni G. Mid-dermal elastolysis: a clinical, histologic, and immunohistochemical study of 11 patients. J Am Acad Dermatol. 2003;48(6):846-851.

5. Gambichler T. Mid-dermal elastolysis revisited. Arch Dermatol Res. 2010;302(2):85-93.

6. Agha A, Hashimoto K, Mahon M. Mid dermal elastolysis: case report and review of the literature. J Dermatol.
1994;21(10):760-766.

7. Neri I, Patrizi A, Fanti PA, Passarini B, Badiali-De Giorgi L, Varotti C. Mid-dermal elastolysis: a pathological and ultrastructural study of five cases. J Cutan Pathol. 1996;23(2):165-169.

8. Bassissi P, Leri A, Ferrari C, Alinovi A. Mid-dermal elastolysis. Eur J Dermatol. 1994;4:537-539.

9. Kirsner RS, Falanga V. Features of an autoimmune process in mid-dermal elastolysis. J Am Acad Dermatol. 1992;27(5 Pt 2):832-834. 